\title{
Gastroesophageal Reflux in Association with Congenital Heart Disease
}

Kenneth M. Weesner, M.D., Amnon Rosenthal, M.D.

\begin{abstract}
The clinical course of 19 infants with severe respiratory symptoms associated with the presence of both congenital heart disease and gastroesophageal reflux is described. Down Syndrome or central nervous system disease was present in 12 of the 19 infants. The identification of reflux as a major or additional cause of the respiratory complications was often overlooked. Medical therapy alone was successful in only one of the 19 patients. Early repair or palliation of the cardiac malformation with or without subsequent antireflux surgical procedure was associated with relief of the symptoms in 13 patients.
\end{abstract}

\section{$R$} SEARATORY SYMPTOMS, including frequent respiratory infections, are common in infants with congestive heart failure due to congenital heart defects. ${ }^{1}$ These symptoms have been attributed to pulmonary edema, decreased lung compliance, impaired elimination of tracheobronchial secretion, and/or compression of the airways by large distended pulmonary arteries. ${ }^{1,2}$ Despite adequate medical or surgical management of the cardiac disease, we have observed persistence of respiratory symptoms in a group of children with congenital heart disease. The symptoms included wheezing, rotating atelectasis, apneic spells, coughing, and vomiting all suggestive of gastroesophageal reflux. ${ }^{3}$ We therefore sought to determine whether gastroesophageal reflux may be an etiologic factor leading to recurrent respiratory infection or persistent respiratory symptoms in some children with congenital heart disease.

From the Pediatric Cardiology Service, Department of Pediatrics, University of Michigan Medical Center, Ann Arbor, Michigan.

Correspondence to: Kenneth M. Weesner, M.D., Division of Pediatric Cardiology, Department of Pediatrics, Bowman Gray School of Medicine, Wake Forest University, 300 South Hawthorne Road, Winston-Salem, NC 27103.

Received for publication October 1982, revised December 1982, and accepted January 1983.

\section{Materials and Methods}

Between September 1977 and January 1981, we retrospectively investigated the possible presence of gastroesophageal reflux in children with congenital heart disease and recurrent respiratory infections or symptoms, persisting after medical treatment of the cardiac disease. The medical record of all consecutive patients evaluated by the Pediatric Cardiology Service at the C.S. Mott Children's Hospital with both congenital heart disease and gastroesophageal reflux were reviewed. Chest $\mathrm{x}$-ray and electrocardiograms were performed in each, other noninvasive studies in 19 , and cardiac catheterization in 16 . Diagnostic procedures performed specifically to detect reflux included barium swallow or upper gastrointestinal series in 19 patients; 14 of these patients had up to three barium studies. Three patients had esophagoscopy and one had 24-hour esophageal $\mathrm{pH}$ monitoring. None had lower esophageal sphincter pressure monitoring.

\section{Resulis}

Of the 19 children with congenital heart disease and recurrent respiratory symptoms with associated gastroesophageal reflux, 8 were male and 11 female. 
The cardiac lesions present in these children were ventricular septal defect in 8 , endocardial cushion defect in 5 , double outlet right ventricle in 2 , and one each with patent ductus arteriosus, tricuspid atresia, total anomalous pulmonary venous connection, and a cardiac tumor. The patients' ages at diagnosis of congenital heart disease ranged from 2 weeks to 9 months, with an average of 3 months. Their ages at diagnosis of gastroesophageal reflux ranged from 2.5 weeks to 2 years, with an average of 5 months.

Presenting complaints included congestive heart failure in 14 , pneumonia in 5 , failure to thrive in 12 , gastrointestinal bleeding in 1 , and cyanosis in 4 . Twelve patients had more than one presenting complaint. Sixteen patients had recurrent pneumonias. Major extracardiac abnormalities included Down Syndrome in 7 , central nervous system disease in 5, Goldenhar's Syndrome in 1, and tracheo-esophageal fistula in 1 . The number of hospitalizations for these patients ranged from 1 to 8 , with an average of 3.8 hospitalizations per patient.

The patients were followed for 1.0 to 3.0 years (mean 1.4 years). Medications received included $\mathrm{Di}$ goxin in 13, chlorothiazide in 12, spironolactone in 12 , theophylline in 6 , phenobarbital in 5 , and phenytoin in 2. Medical treatment in gastroesophageal reflux included upright positioning and thickened feedings in all 19 patients. Our patients did not receive antireflux drugs such as bethanachol.

Cardiac surgical repair or palliation was performed in 16 patients at ages 3 weeks to 14 months (mean 5 months). In 9 of the 16 patients, respiratory symptoms attributed to gastroesophageal reflux improved between one and 12 months after heart surgery. Among the others, four required gastroesophageal procedures, two were lost to follow-up, and one remained symptomatic after cardiac surgery. In 10 of 16 patients, respiratory symptoms attributed to gastroesophageal refux prolonged hospitalization time after cardiac repair beyond the customary two weeks. Six patients required gastroesophageal reflux procedures; five of these had neurologic abnormalities. Age at surgery for gastroesophageal reflux ranged from 3 weeks to 2.0 years (mean 11 months). Operations for reflux included an Allison procedure in one patient as a first step and Nissen fundoplication procedures in 5, one with a simultaneous Hill posterior gastropexy. Two of the five patients with neurologic abnormalities improved, two died from recurrent pneumonia, and were noted to have persis- tent reflux prior to death. One patient's respiratory symptoms subsequently improved after repair of his cardiac lesion. Respiratory symptoms improved spontaneously with medical antireflux therapy in only one patient, with no requirement for either cardiac surgical or gastroesophageal reflux surgical intervention.

\section{Discussion}

Respiratory symptoms and failure to thrive are commonly associated with cardiac lesions causing congestive heart failure in infants, especially those with large left-to-right shunts. ${ }^{1,2}$ Similar respiratory symptoms and chronic pulmonary disease have been described in children with gastroesophageal reflux, with or without other conditions. ${ }^{3-6}$ Gastroesophageal reflux has been reported to occur frequently following repair of tracheoesophageal fistula in infancy ${ }^{7,8}$ and in neurologically damaged children. ${ }^{9}$ However, only two previous reports have described a number of children with gastroesophageal reflux and congenital heart disease. ${ }^{10,11}$ The etiology of gastroesophageal reflux in our patients with congenital heart disease is unclear. While one patient had prior repair of a tracheoesophageal fistula, and 12 may be considered to be neurologically abnormal, the remaining six infants had no other associated extracardiac abnormality. Since respiratory symptoms caused by the cardiac disease and reflux are often similar, the identification of reflux as an additional or major cause of the symptoms was often overlooked.

Although the number of patients reported is not large, there is reason to believe that there were a number of patients with congenital heart disease and gastroesophageal reflux who were not detected, due to the insensitivity of the diagnostic methods used.

All 19 patients had barium studies. Fourteen, however, required up to three separate barium studies, 1 esophageal pH monitoring, and 1 esophagoscopy to make the diagnosis. Recent reviews of the effectiveness of various diagnostic studies ${ }^{12.13}$ to detect gastroesophageal reflux suggest that a single barium study may have a 70 per cent false negative rate. Radionuclide scanning is a useful technique, but 24hour esophageal $\mathrm{pH}$ monitoring with lower esophageal sphincter pressure manometry appears to be the most accurate method in establishing the diagnosis. ${ }^{12-14}$ Better definition of the incidence of gastroesophageal reflux in infants and children with congenital heart disease or specific cardiac lesions would 


\section{WEESNER \& ROSENTHAL}

require a prospective use of these sensitive techniques.

We conclude that gastroesophageal reflux may be observed in children with congenital heart disease, especially those with ventricular septal defect or endocardial cushion defect, and in association with neurologic impairment. In the presence of recurrent respiratory symptoms, recurrent pneumonia, and failure to thrive, children with cardiac disease may benefit from evaluation for gastroesophageal reflux. Such evaluation should include 24-hour $\mathrm{pH}$ monitoring. If significant reflux is documented, these patients should be given a trial of medical management including thickened feeds, appropriate positioning (prone on 30-degree slant board) and perhaps also drug therapy such as bethanechol. ${ }^{11}$

\section{References}

1. Talner NS. Heart failure. In: Moss AJ, Adams FH, Emmanouilides GC, eds. Heart disease in infants and adolescents. 2nd ed. Baltimore: Williams \& Wilkins, 1977;660-71.

2. Keith JD. Congestive heart failure. In: Keith JD, Rowe RD, Vlad P, eds. Heart disease in infancy and childhood. 3rd ed. New York: MacMillan, 1978;163-85.

3. Danus $O$, Casar $C$, Larrain A, et al. Esophageal reflux-an unrecognized cause of recurrent obstructive bronchitis in children. J Pediatr 1976;89:220-4.
4. Christie DL, O'Grady LR, Mack DV. Incompetent lower esophageal sphincter and gastroesophageal reflux in recurrent acute pulmonary disease of infancy and childhood. J Pediatr 1978;93:23-7.

5. Shaprio GG, Christie DL. Gastroesophageal reflux in steroid dependent asthmatic youths. Pediatrics 1979;63:207-12.

6. Christie DL. Respiratory disease associated with esophageal reflux. Pediatrics 1979;63:344-5.

7. Shermeta DW, Whitington PF, Seto DS, et al. Lower esophageal sphincter dysfunction in esophageal atresia: nocturnal regurgitation and aspiration pneumonia. J Pediatr Surg 1977:12:871-6.

8. Whitington PF, Shermeta DW, Seto DS, et al. Role of lower esophageal sphincter incompetence in recurrent pneu. monia after repair of esophageal atresia. J Pediatr $1977 ; 91: 550-4$.

9. Schatzlein MH, Ballantine TV, Thirunavukkarasu S, et al. Gastroesophageal reflux in infants and children. Arch Surg 1979;114:505-9.

10. Jolley SG, Herbst J, Johnson DG, et al. Surgery in children with gastroesophageal reflux and respiratory symptoms. J Pediatr 1980;96:194-8.

11. Johnson DG, Jolley SG. Gastroesophageal reflux in infants and children: recognition and treatment. Surg Clin North Am 1981;61:1101-15.

12. Weissbluth M. Gastroesophageal reflux. Clin Pediatr 1981; 20:7-13.

13. Arasu TS, Wyllie R, Fitzgerald JF, et al. Gastroesophageal reflux in infants and children: comparative accuracy of diagnostic methods. J Pediatr 1980;96:798-803.

14. Sondheimer JM. Continuous monitoring of distal esophageal $\mathrm{pH}$ : a diagnostic test of esophageal reflux in infants. J Pediatr 1980;96:804-7. 